\title{
ATYPICAL ORGANIZATION OF PRAXIS AND LANGUAGE: A LOOK BACK
}

\author{
Gregory Króliczak ${ }^{1}$, Mikołaj Buchwald ${ }^{1}$, Michał Klichowski ${ }^{1,2}$, \\ Agnieszka M. Nowik ${ }^{1}$, and Brian J. Piper ${ }^{3}$ \\ ${ }^{1}$ Action and Cognition Laboratory, Faculty of Psychology and Cognitive Science, \\ Adam Mickiewicz University, Poznań, Poland \\ ${ }^{2}$ Learning Laboratory, Faculty of Educational Studies, \\ Adam Mickiewicz University, Poznań, Poland \\ ${ }^{3}$ Department of Medical Education, \\ Geisinger Commonwealth School of Medicine, Scranton, PA, USA
}

\begin{abstract}
Atypical representations of praxis and language were studied in two forms and combinations: bilateral organization, and right lateralization, independently for each function; when the atypically represented praxis dissociates from typically lateralized language; and when both praxis and language have atypical forms. Direct differences between bilateral and right-lateralized representations were either marginal (for praxis), or nonexistent (for language). Because atypical organization of praxis is over twice as frequent as language in its atypical form, sample size might be an issue only for the latter
\end{abstract}

Gregory KróliczaK, https://orcid.org/0000-0001-6121-0536; Mikolaj Buchwald, https:// orcid.org/0000-0001-8764-0032; MichAL KLICHOWSKI, https://orcid.org/0000-0002-1614-926X; AgniesZKa M. NowiK, https://orcid.org/0000-0002-3872-1685; BRIAN J. PIPER, https://orcid.org/00000002-2295-445X.

Correspondence concerning this article can be addressed to Grzegorz Króliczak, Wydział Psychologii i Kognitywistyki UAM, ul. Szamarzewskiego 89, 60-568 Poznań, Poland; e-mail: krolgreg@ amu.edu.pl.

This study was supported by the National Science Centre grant Maestro (2011/02/A/HS6/00174) and the NIH/NINDS grants (NS053962 and R01 NS053962). The equipment used for data analyses was funded by the Ministry of Science and Higher Education grant (6168/IA/128/2012).

Handling editors: Magdalena SzubielsKa \& Pawel StróżaK, John Paul II Catholic University of Lublin.

Received 7 July 2021. Received in revised form 5 Nov. 2021. Accepted 24 Nov. 2021. Published online 12 Feb. 2022. 
(as atypical organization of language is very rare). Group averages in their dissociations, and associations in atypical forms, revealed the expected representations of the two functions. These outcomes indicate that merging the two atypical representations of praxis, or language, into one atypical group can reveal the critical aspects of their atypicality, including subcortical contributions, without seriously impeding correct interpretation of the essential underlying neural mechanisms.

Keywords: tool use gestures; verbal fluency; hand dominance; interrelations; functional asymmetries; lateralization; segregation; dissociation.

The relationships between lateralized cognitive functions in the human brain have been extensively studied with the use of disparate neuroimaging approaches for over a decade (e.g., Badzakova-Trajkov et al., 2010; Króliczak et al., 2011; Vingerhoets et al., 2013; Cai et al., 2013; Haberling \& Corballis, 2015; Karlsson et al., 2019; Gerrits et al., 2020; Króliczak, Piper et al., 2020; Króliczak et al., 2021a; for a review and meta-analysis, see also Króliczak et al., 2019, and Osiurak et al., 2021). Yet, despite great strides that have been made in uncovering the association and segregation patterns of the typically left hemisphere dominant functions, such as language or higher-order motor skills (praxis), and typically right hemisphere dominant functions, such as spatial attention or face recognition, relatively little is known about factors contributing to the emergence of their different, e.g., reversed phenotypes. Moreover, their thorough and exhaustive categorizations are also missing. Without the latter, raw incidence rates of hemispheric functional dominance in righthanders and lefthanders are not that helpful, and there is still a clear need for simultaneous studies of the shifts in the neural organization of several, putatively related versus independent cognitive skills. Otherwise, it will not be known whether or not atypical laterality of a given function, e.g., right lateralization of language, is accidental (or driven by an unknown or random factor; e.g., Goldenberg, 2013) and has any impact on the organization or laterality of other functions, e.g., praxis (Vingerhoets, 2019; see also Króliczak, Potok et al., 2020). In short, studying the neural underpinnings of several cognitive functions in the same individuals, especially the ones having their atypical, bilateral or reversed, organization seems to be key to understanding the overall functional architecture of the human cerebral cortex, as well as the contribution from critical subcortical structures.

Atypical, bilateral organization or right lateralization of language is rather rare, being more common in lefthanders (Carey \& Johnstone, 2014), but its incidence rates are not that impressive even in the latter group (Woodhead et al., 2021; Knecht et al., 2000). In fact, the vast majority of lefthanders still demonstrate - quite typical - left lateralization of language and praxis, and right lateralization of other functions, such as attention, face recognition or prosody processing in their brains 
(see Table 1 of Vingerhoets, 2019; cf. Króliczak, Piper et al., 2020; but see also Johnstone et al., 2021, who demonstrate that typical lefthanders are less lateralized than righthanders). As also shown quite recently, in the majority of ambidextrous individuals (mixedhanders), the praxis and language functions are quite typically represented, too (Króliczak et al., 2021a). This is a reason why researchers are often forced to collapse across individuals with bilateral organization, and reversed lateralization of functions while referring to atypical phenotypes of their interest. Indeed, merging the very rare individuals showing mirror-reversed laterality of a given function with the ones demonstrating the more balanced contribution from both hemispheres may sometimes be the only solution for obtaining statistically significant results at a group level. Yet another problem inherent in reporting the outcomes from the atypical groups are disparate cutoff points used to assign individuals to the atypical category. For these and other reasons, for example, different approaches to calculating laterality indices (LI scores) before assigning individuals to a given group, reporting mean group activity, or central tendencies from such heterogenous, atypical individuals may impede correct interpretation of the underlying neural mechanisms (e.g., Vingerhoets, 2019), and ultimately be detrimental for developing effective neuro-rehabilitation techniques and neuroprostheses.

In order to overcome such limitations, here we extended the sample of atypical individuals from our recent work on the links between the neural representations of manual praxis and language production networks, regardless of handedness (Króliczak et al., 2021a), by adding participants from Króliczak and collaborators (2011). A persuasive justification for using such an approach was already provided in our earlier report limited only to lefthanders (Króliczak, Piper et al., 2020). In short, not only are the outcomes from the used paradigms similar enough, but there are also five individuals in that sample with praxis and/or language atypically organized, with one of them also showing their clear dissociation. We hoped that the inclusion of these additional participants would provide enough statistical power to detect group differences between typical (left lateralized) and mirror-reversed (right lateralized), or even bilaterally organized, praxis and language functions. We were also interested to know whether the typical organization of language in individuals with atypically organized praxis would be (at least qualitatively) indistinguishable from the one observed in participants with both praxis and language typically organized. Finally, we also wanted to show for the first time the group data for participants in whom both of these functions are atypically organized. 


\section{METHOD}

\section{Participants}

One hundred and forty healthy volunteers ( 72 women, $68 \mathrm{men}$; nearly equally distributed across handedness groups), mainly native speakers of Polish (only 15 native speakers of English), 52 righthanders (with mean age $\left[M_{\mathrm{A}}\right]=22.1$, and standard deviation $[S D]=1.9$ years $), 57$ lefthanders $\left(M_{\mathrm{A}}=23.5, S D=5.1\right)$, and 31 mixedhanders $\left(M_{\mathrm{A}}=22.9, S D=4.2\right)$, with age range $=29$, min. 18 and $\max .47$ years, were tested in praxis and language localizer/task scans of two larger functional magnetic resonance imaging (fMRI) projects. While all volunteers considered themselves to be healthy, additional exclusion criteria involved the lack of any medically documented history of psychiatric or neurological disorders, no contraindications to undergoing magnetic resonance imaging (MRI), and no gross malformations obvious in the obtained scans of their brains. A relatively large group of lefthanders and mixedhanders was included in order to increase the probability of finding as many individuals with atypical dominance for praxis and/or language, or combinations of thereof, as possible (e.g., Kimura, 1983; Johnstone et al., 2020).

As shown by the revised Edinburgh Handedness Inventory (EHI) by Oldfield (1971), our participants varied from strongly right handed to strongly left handed, and their LIs (laterality indices) were as follows: righthanders ${ }_{(52)} \mathrm{EHI} \mathrm{LI}=+89.1$, $S D=16.3$; lefthanders ${ }_{(57)} \mathrm{EHI} \mathrm{LI}=-83.0, S D=15.4$; and mixedhanders ${ }_{(31)} \mathrm{EHI} \mathrm{LI}=$ $=0.2$, and $S D=21.4$. We used the following criteria from our earlier work (Króliczak et al., 2021a): +100 indicates complete right hand dominance, -100 complete left hand dominance, and an index between +33.3 and -33.3 indicates mixed handedness. Informed written consent was obtained from each volunteer before their participation in these projects, approved by the Ethics Committee for Research Involving Human Subjects at the University of Oregon, and the Bioethics Committee at Poznań University of Medical Sciences (Ethical Approval No. 63/12). As such, all the study protocols were consistent with the WMA principles included in the 2013 Declaration of Helsinki. 


\section{Tasks}

\section{Tool Use Pantomimes}

Our participants were requested to plan and execute tool use pantomimes, in response to stimuli (tool images, or action words) shown via a coil-mounted mirror on a display behind the scanner. In the control tasks participants were requested to manually count parts of non-tool objects, or process non-action words and refrain from performing any gesture (for more details, see Króliczak et al., 2021a; Króliczak, Piper et al., 2020; Przybylski \& Króliczak, 2017; Króliczak et al., 2011).

\section{Covert Word Generation}

A cued verbal fluency test was used, typically with six 30-s task blocks, interchanged with six 30-s rest blocks (as in Króliczak et al., 2011). Participants silently (subvocally) generated as many words as possible, in response to presented letters (A, E, G, H, K, L, M, or T), shown pseudo-randomly above the fixation cross on a display watched via a coil-mounted mirror. Nearly half of the participants had additional four 30-s blocks of a control task wherein, in response to scrambled letters, they covertly generated the (Polish) non-word "zaza". The common baseline or control task, i.e., rest blocks were pseudo-randomly introduced between the task blocks.

All digital materials (more specifically, their Polish versions) relevant for performance of the tasks described above are publicly available at https://osf.io/63hjt (Króliczak et al., 2021b). If any clarification is needed, the reader can also contact the corresponding author.

\section{FMRI Data Acquisition and Analyses}

One of the two Siemens scanners-a 3-Tesla Allegra or 3-Tesla Trio-located at the Lewis Center for Neuroimaging at University of Oregon in Eugene, or in the Laboratory of Brain Imaging at the Nencki Institute in Warsaw, respectively, were used for these experiments. The echoplanar BOLD images were obtained using T2*-weighted segmented gradient-echo imaging sequence. Standard, anatomical images were collected with the use of a 3D T1-weighted magnetization prepared rapid gradient echo (MP-RAGE) pulse sequence, and additional fast spin echo T2-weighted anatomical images were also acquired, to improve the registration process. All the specific imaging parameters can be found elsewhere (Króliczak, Piper et al., 2020; Króliczak et al., 2021a). 
The data pre-processing/processing steps, and their analysis types, were also the same as described elsewhere (Króliczak, Piper et al., 2020; Króliczak et al., 2021a). FMRIB's Software Library (FSL) v4.1.4, v5.0.6, or later (http://fsl.fmrib.ox.ac.uk/ fsl/fslwiki; Jenkinson et al., 2012) was used to obtain statistical parametric maps of task-related neural activity. As in our earlier study (Króliczak et al., 2021a), we decided to present the obtained significant results thresholded non-parametrically at halves of the maximum $Z$ statistics revealed in each contrast, but not lower than $Z>2.7$ (Thirion et al., 2007), a threshold still giving reliable, and easily replicable results (cf. the criticized $Z>2.3$ value, Eklund et al., 2016; note that the lower the $Z$ value, the greater the cluster size). This is justified because none of the reported contrasts was empty at the more conservative $Z>3.1$ threshold. The most conspicuous difference was then the extent of neural activity (cluster size), not necessarily the different and separate loci of neural activity (i.e., the location and number of identified activity clusters).

\section{Regions of Interest (ROIs) and fMRI-based LIs}

Cytoarchitectonically defined left and right Brodmann areas [BAs]40, consisting of divisions PF and PFm of the inferior parietal lobule (IPL, critical for praxis skill production), as well as BAs 44 and 45 combined (as both of these two areas are critical for language production), as implemented in FSL, were chosen for region of interest (ROI) analyses. Each of these ROIs was first thresholded at the $50^{\text {tho }} \%$ of its maximum probability value, with the use of a relevant function from "fslmaths" operations. Subsequently, custom-made scripts which utilized "fslmaths", as well as "fslstats" functions, were used for calculating functional MRI LIs (fMRI-based laterality indices). Both LIs based on voxel counts (the extent of neural activity), and neural signal amplitudes (the strength of neural activity), were computed in the two critical ROIs, using the $[(\mathrm{L}-\mathrm{R}) /(\mathrm{L}+\mathrm{R})] \times 100$ formula at six different thresholds, and then averaged (as in Króliczak et al., 2021a). An fMRI LI of +100 indicates complete left laterality (typically associated with the hemisphere dominant for language and praxis), -100 complete right or reversed laterality, and 0 an equally balanced involvement of both ROIs (with cutoff points at +33.3 and -33.3 ).

\section{Clarifications and Disclosures}

All remaining clarifications and disclosures related to participation, assignments of participants to our disparate projects, and the utilized tasks can be found elsewhere (Króliczak, Piper et al., 2020; Króliczak et al., 2021). All the analyses performed, 
as well as the outcomes presented in this project, are completely new. Namely, they involve more specific, and larger subsamples of participants with atypical organization of functions and are different from any of our previous reports.

\section{RESULTS}

\section{Statistics for Distributions, Associations and Dissociations of fMRI LIs for Praxis and Language in Two Cytoarchitectonic ROIs}

\section{Praxis fMRI LIs}

Out of 140 participants tested, as many as 44 had atypical representation of praxis (27 women; 24 lefthanders regardless of their gender), with Mean Laterality Index $\left(M_{\text {fMRI LI }}\right)=-27.8$, Standard Deviation $(S D)=43.4$, Range $(R)=133$, Min. $=-100$, Max. $=33$. As many as 19 of them had right-lateralized praxis: $M_{\mathrm{fMRI} \mathrm{LI}}=-71.1, S D=22.1, R=63$, Min. $=-100$, Max. $=-33$. The remaining 25 participants had bilaterally organized praxis: $M_{\mathrm{fMRI} L I}=5.2, S D=19.9, R=62.5$, Min. $=-29.5$, Max. $=33$.

\section{Language fMRI LIs}

Out of 140 participants, only 19 (12 women; 15 lefthanders) had atypical representation of language: $M_{\mathrm{fMRI} \mathrm{LI}}=-31.1, S D=39.7, R=130.5$, Min. $=-100$, Max. $=30.5$. Over a half of them, 10 had bilaterally organized language: $M_{\mathrm{fMRI} \text { LI }}=4.2, S D=18.4, R=53.2$, Min. $=-22.7$, Max. $=30.5$. The remaining 9 participants had right-lateralized language: $M_{\mathrm{fMRI} \mathrm{LI}}=-63, S D=21.6, R=68$, Min. $=-100$, Max. $=-32$.

\section{Dissociations of Atypically Represented Praxis From Typically Lateralized Language}

As many as 28 participants (17 women, 11 lefthanders regardless of sgender) revealed a dissociation of atypically represented praxis from typically lateralized language. Their descriptive statistics are as follows: Praxis $M_{\mathrm{fMRI} \mathrm{LI}}=-15, S D=41$, $R=133$, Min. $=-100$, Max. 33; Language $M_{\mathrm{fMRI} \mathrm{LI}}=84.9, S D=13.2, R=55.1$, Min. 44.9, Max. $=100$. 


\section{Associations of Atypically Represented Praxis and Language}

Sixteen of the tested participants (10 women, 13 lefthanders) had both praxis and language represented in their atypical forms. Their descriptive statistics are as follows: Praxis $M_{\mathrm{fMRI} \mathrm{LI}}=-50.1, S D=39.4, R=130$, Min. $=-100$, Max. $=30$; Language $M_{\mathrm{fMRI} L I}=-36, S D=38.9, R=126.5$, Min. $=-100$, Max. 26.5.

\section{FMRI Activity Maps}

The outcomes observed for praxis in tool use pantomimes (contrasted with a control manual part counting task [Przybylski \& Króliczak, 2017], or abstract mental actions [Króliczak \& Frey, 2009]), and for language (obtained from a contrast of silent word production with resting baseline, as most consistent with the Wada test; e.g., Chlebus et al., 2007) are almost indistinguishable from the ones reported elsewhere (Króliczak et al., 2021a). This is the case also for the atypically represented functions, and it is not surprising because as many as 39 participants for the praxis task, and 15 participants for the language tasks overlap between the two studies. The results shown in Figure 1A - for atypical praxis, and 1B - for atypical language, can be directly compared with the ones from Figure $3 \mathrm{C}$ and D of Króliczak and collaborators (2021a), respectively. The panels in Figure 1 AB display the praxis- and language-related neural activity when all participants with their atypical forms or representations are included in their group average.

As shown in Figure 1A, the neural activity in atypically represented praxis (here: combining both the bilateral and right lateralized group) was largely balanced, though leaning towards some right-hemisphere advantage, with the exception of the exclusive involvement of the anterior division of the right inferior frontal sulcus (IFSa), extending slightly to area 45 (of the inferior frontal gyrus; IFG). As shown in Figure 1B, the neural activity in atypically represented language (again, combining both the bilateral and right lateralized group) was nearly mirror-reversed, as qualitatively compared to its typical organization. Specifically, except for mid to posterior IFS, and ventral premotor cortex (PMv, subdivisions 6r, and 6v), as well as the anterior and mid insular cortex (AVI, and MI), the frontal activity was nearly exclusively right lateralized. Yet, the ultimate goal of this study was to divide the participants with atypically represented functions into those with bilateral, and right-lateralized representations of praxis and language. 


\section{Figure 1}

Neural Representations of Praxis and Language in Their Atypical Forms, Including Their More Specific Subdivisions

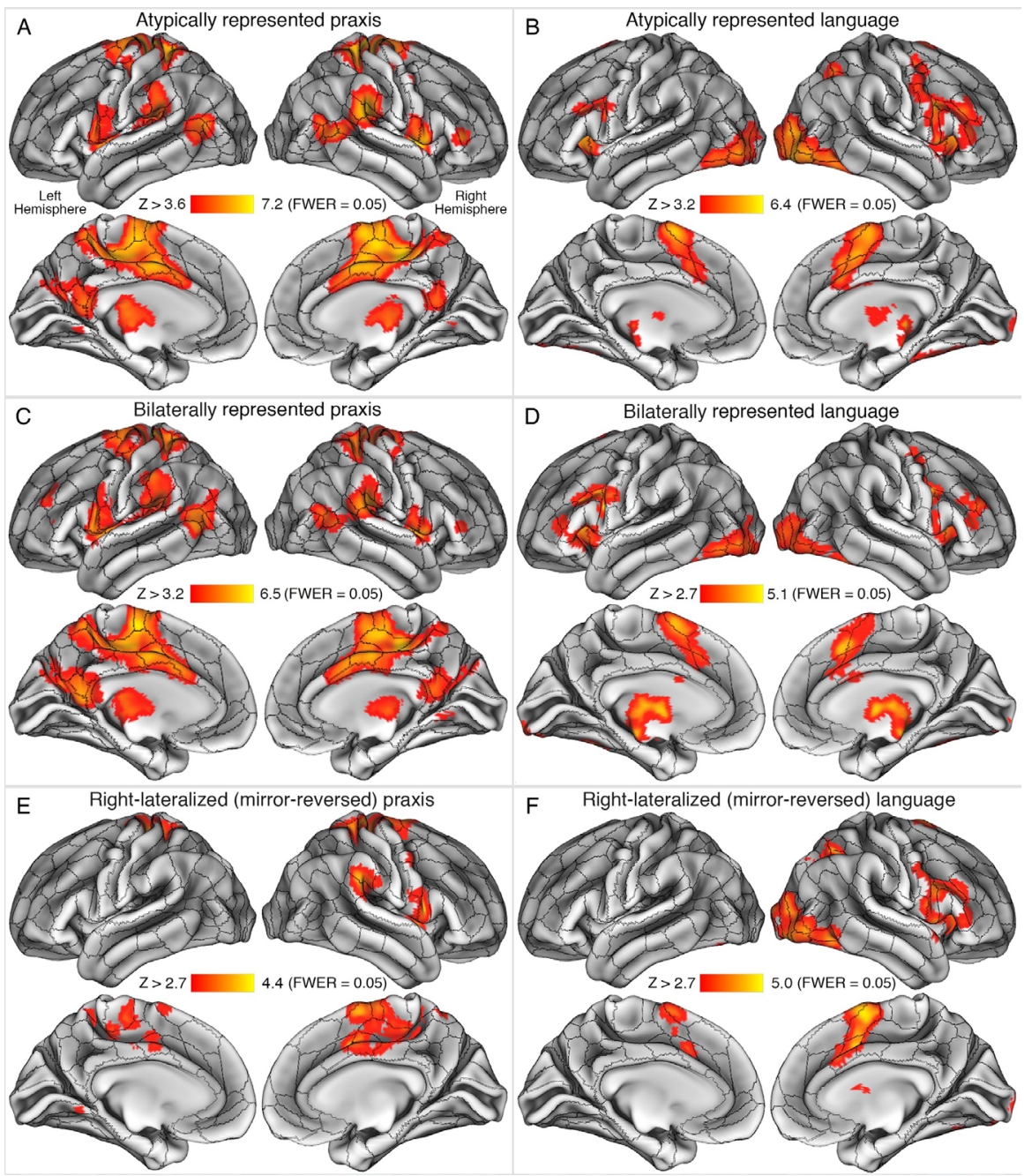

Note. As in our earlier report (Króliczak et al., 2021a), the groups are differentiated based on fMRI LIs averaged across voxel count and signal intensity (VCSIs). (A) Nearly balanced neural activity in atypically represented praxis, except for some advantage for just few right-hemisphere areas, and the exclusive involvement of right IFSa. (B) Nearly mirror-reversed neural activity in atypically organized language, except for mid to posterior IFS, ventral areas 6, and anterior insular cortex. (C) Bilaterally organized praxis. (D) Bilaterally organized language. (E) Right-lateralized praxis. (F) Right-lateralized language. For a description of these outcomes, see the main text. Only volumetric surface renderings are shown, thresholded non-parametrically at half of the maximum $Z$ value, but not lower than $Z>2.7$, and always with a corrected cluster significance threshold of $p=0.05$. 
The group average for the bilaterally represented praxis, as seen in Figure 1C, showed a clear additional contribution from area 46 on the left, and the increased activity in the temporo-parieto-occipital junction (namely, in its TPOJ3 subdivision) extending to the angular gyrus (its PGs subdivision). In the case of right-lateralized praxis, the outcomes shown in Figure 1E were limited to the right-hemisphere in the supramarginal gyrus (SMG) and its immediate (also opercular) vicinities, posterior IFG, mid insular cortex, and a small cluster in area 55b. The remaining, more superior contributions were largely bilateral, and involved both subdivisions of the dorso-dorsal, and medio-dorsal streams (Rizzolatti \& Matelli, 2003; Goodale et al., 2005; Binkofski \& Buxbaum, 2013).

The bilaterally organized language, as shown in Figure 1D, was truly balanced across all areas significantly engaged in the task. In the case of right-lateralized language, the outcomes shown in Figure 1F are largely the same as in 1B, but not surprisingly limited nearly exclusively to the right hemisphere.

A direct contrast of praxis in its typical and bilateral form showed no significant differences in neural activity whatsoever, in neither of the directions. Yet, as depicted in Figure 2A, a contrast of praxis in its typical, left-lateralized form, and right-lateralized, mirrored-reversed form revealed both the advantage of critical left parietal areas (i.e., PF, PFt, and partly PFm, more inferior OP4, PFop and PFcm parcels, as well as more superiorly in AIP, IP2, and even 7PC), and temporal and/ or further parietal areas (mainly FST, TPOJ2, as well as a small cluster in PGi and PGs). Moreover, this contrast revealed a small frontal, ventral cluster (located nearly exclusively in area 6r). There were also significantly different changes in neural activity detected on the medial parietal surface of the left hemisphere (extending from V6, via DVT and POS2, through 7Am). These outcomes are shown in warm, red-to-yellow colors on the lateral and medial surfaces on the left of panel A. The inverse contrast, i.e., of praxis in its right-lateralized and left-lateralized form, revealed no significant clusters of neural activity (as indicated by " 0.0 " next to cold, dark-to-light blue color bar in panel A). 


\section{Figure 2}

Areas Differentiating Praxis and Language in Their Typical and Mirror-Reversed Forms, as Well as Their Representations When They Dissociate, or Associate, but Only in Their Atypical Forms

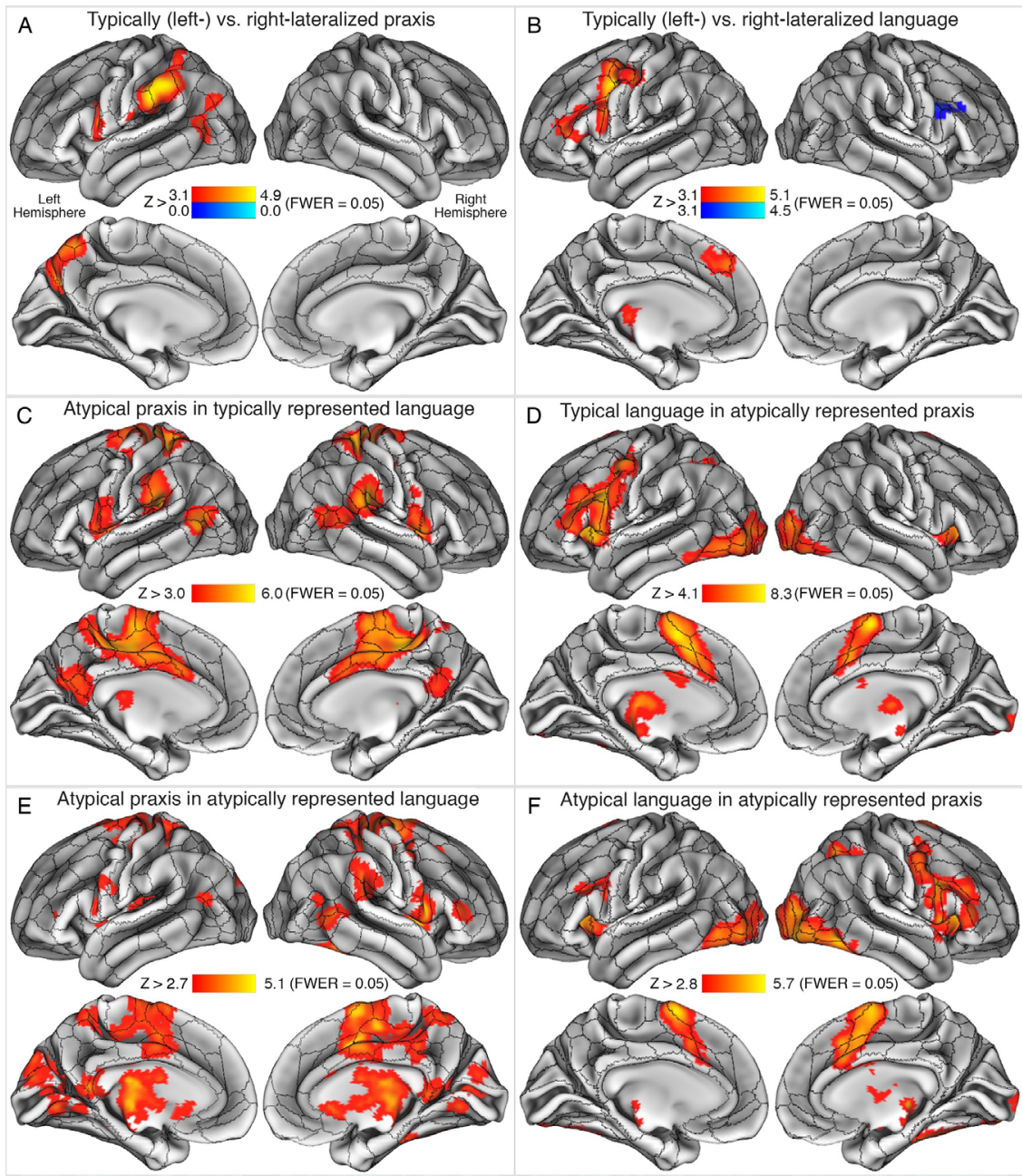

Note. (A) A direct contrast of praxis representations in their typical and right-lateralized forms. The expected, significantly greater contributions from critical left parietal and temporal areas were revealed for typical praxis. No greater contributions for praxis in its right-lateralized form were revealed. (B) The expected advantage of left-hemisphere areas in typical, and some right-hemisphere frontal areas in right-lateralized representations of language. Warm colors (red to yellow) depict significantly greater neural activity for typically represented praxis or language, and cold colors (dark to light blue) depict significantly greater neural activity for right-lateralized language. (C) Praxis-related activity in its atypical form in individuals who at the same time show (D) typically represented language. Thus, panels $\mathrm{C}$ and $\mathrm{D}$ depict the most common praxis-language dissociation patterns. (E) Praxis-related activity in its atypical form, when it is associated with (F) language in its atypical form. Thus, panels $\mathrm{E}$ and $\mathrm{F}$ can be linked to praxis-language associations, but only when both of these functions are in their atypical forms. Of note is the substantially greater contribution from subcortical areas (including the thalamus and basal ganglia) in such cases of atypical praxis. 
A direct contrast of language in its typical and bilateral form (not shown here) revealed only one small cluster of neural activity in left BA44. The inverse contrast (also not shown) disclosed only some contributions from the thalamus and basal ganglia. Yet, a direct contrast of language in its typical and right-lateralized form was more informative. Figure 2B depicts the expected advantage of left-hemisphere frontal areas in typical (shown in warm colors), and some right-hemisphere frontal areas in right-lateralized (mirror-reversed; shown in cold colors) language representation.

A direct contrast between the two atypical - bilateral and mirror-reversed (right-lateralized) praxis phenotypes was empty in both directions at $Z>3.1$. (Yet, for completeness it should be stated that for the mirror-reversed, i.e., right-hemisphere praxis, some greater involvement of lower-level visual areas was found bilaterally at $Z>2.7$.) Notably, a direct contrast between the bilateral and right-lateralized language phenotypes was completely empty in both directions even at $Z>2.7$.

The remaining panels of Figure 2 display the following phenotypes or neural activity patters: panel $2 \mathrm{C}$ shows a group average for atypically represented praxis in individuals who at the same time have quite typical organization of language, as depicted in panel 2D; and panel 2E shows a group average for atypically represented praxis in individuals who at the same time also have atypical organization of language, depicted in panel $2 \mathrm{~F}$. The outcomes in panels $2 \mathrm{C}$ and $2 \mathrm{D}$ are nearly as expected (based on findings shown in Figure 1), and the results reported earlier by our group (Króliczak et al., 2021a). A little bit more surprising are the results presented for the first time ever in panel 2E. Specifically, the group average for atypical representation of praxis - in individuals who also have atypical representation of language - in addition to corroborating the pattern of contributions from cortical areas, reveals greater than expected changes in neural activity in subcortical structures. Yet, as shown in panel 2F, this is not the case in their atypical representations of language.

\section{DISCUSSION}

The main goal of this study was to address a concern that reporting mean neuroimaging group activity, or any central tendencies, for heterogenous groups of individuals with atypically organized or lateralized functions (e.g., as in Króliczak et al., 2021a) may impede the proper understanding of the underlying neural or cognitive mechanisms specific for a particular atypical individual, or a subgroup she or he belongs to (see Biduła et al., 2017; and Vingerhoets, 2019, cf. Johnstone et al., 2021; see also Mazoyer et al., 2014). Specifically, such lumping or merger could 
lead to collapsing individuals with rather disparate neural phenotypes into just one category, and confound attempts to elucidate factors contributing to the emergence of atypical organization/lateralization of the studied functions, and efforts to reveal their unique neural characteristics (which may not show up in such group data). As a result, it can be also detrimental for developing efficient, patient-based, neuro-rehabilitation techniques or neuroprostheses (cf. Liew et al., 2018).

To tackle and alleviate such concerns, we assembled neuroimaging data from all our earlier projects on praxis and language representations in healthy individuals (e.g., Króliczak et al., 2011; Króliczak et al., 2021a), divided first their participants into the ones having typical (left-lateralized) and atypical (i.e., combining both bilateral and right-sided) organization of functions (see Figures $1 \mathrm{~A}$ and 1B), and subsequently also split the atypical groups into individuals with either bilateral or right-lateralized praxis (see Figures $1 \mathrm{C}$ and $1 \mathrm{E}$ ) and language representations (see Figures $1 \mathrm{D}$ and $1 \mathrm{~F}$ ) for their direct comparisons. The split was based on laterality indices from two cytoarchitectonic regions critical for the control of praxis or language production. Four major groups of individuals can be distinguished based on using such criteria. The first one consists of two subgroups: with either bilateral or right-lateralized praxis, regardless of the organization/lateralization of language. The second one also consists of two subgroups of individuals: showing either bilateral or right-lateralized representations of language, but regardless of the accompanying (typical or atypical) representation of praxis. Because the incidence rates are over twice as high in praxis compared to language (Króliczak et al., 2021a), the third, quite numerous group consists of individuals in whom the two functions dissociate, that is with atypically represented praxis and typical, i.e., left-lateralized language. (Further split of this group would require a completely different criterion, e.g., above or below zero for praxis; e.g., Johnstone et al., 2021.) Finally, the fourth group consists of individuals who have both praxis and language atypically organized or lateralized, with no obvious criterion for dividing this group any further (because many individuals with right-lateralized praxis have balanced organization of language).

Three pieces of evidence alleviating the "merging concern" are as follows. Regardless of whether bilaterally organized praxis or language is considered, their comparisons with typically represented, left-lateralized praxis or language reveal little, if any, differential engagement of areas (i.e., cortical subdivisions specialized for processing of a given function) or networks (combining larger sets of areas) usually associated with praxis or language processing. Likewise, the same-i.e., virtually null - effects emerge from their direct comparisons with atypically represented, right-lateralized praxis or language. A positive interpretation of these outcomes is such that individuals with bilateral organization of functions engage the same praxis and language networks as people with typical left-lateralized, and 
atypical right-lateralized functions, but to a lesser degree. If the effect for praxis is similar to the one observed for language (Biduła et al., 2017; i.e., the more bilateral the representation, the fewer number of voxels are involved), we can even speculate that this means both smaller extents of neural activity, and perhaps even smaller amplitudes (increases) of signal changes within the same-anatomically speaking, largely symmetrical - neural regions. Consistent with this notion is our additional observation that contrasting only individuals with left-lateralized and right-lateralized functions reveals neural areas or their networks identical with or similar to the ones obtained for contrasting groups with typical lateralization and the one involving the merged atypical (i.e., bilateral plus right-lateralized) group. While these outcomes are not identical with the ones obtained by Króliczak and collaborators (2021a), they do reveal the areas that are most critical for the function in question in typical phenotypes - i.e., both for praxis and language, and atypical phenotypes - but mainly for language organization (see Figure 2AB here, and 3EF in Króliczak et al., 2021a; see also Johnstone et al., 2020).

The latter point leads us to an alternative, negative interpretation of at least two pieces of current evidence that would be consistent with the "merging concern" (Vingerhoets, 2019). They are as follows. The lack of any major differences in direct comparisons of the bilateral praxis and language phenotypes with their leftand right-lateralized counterparts could be due to greater variability, known to be present among individuals with atypically organized functions (Biduła et al., 2017; see also Karlsson et al., 2019). Coherent with this notion is also an observation that the only consistent outcomes are in the "left- vs. right-lateralized" direction of our neuroimaging contrasts. The inverse contrasts (i.e., including individuals with right- vs. left-lateralized praxis, or language) either show no effects for praxis, or just a small subdivision of the core language network (Figure 2B, dark to light blue). While the somewhat disappointing effect for language can be easily explained by the small sample size of the right-lateralized language group $(N=9)$, the same cannot be said about the right-lateralized praxis group $(N=19)$. The just reported numbers for group numerosity, in the context of the obtained neural activity patterns - quite coherent for language but not praxis, point to one more interpretation which is partly inconsistent with the "merging concern". Namely, language representations in the brain are substantially less variable (at least for language production studied here) than praxis representations, and therefore lumping is less risky for atypically represented language.

Yet, the argument presented above can be weakened by additional positive interpretations stemming from comparisons of group averages for atypically represented praxis. Figures $1 \mathrm{C}$ and $1 \mathrm{E}$, as well as $2 \mathrm{C}$ and $2 \mathrm{E}$ show numerous common components of the core praxis network or praxis-related areas, regardless of whether 
they come from individuals with right-lateralized, bilateral or typical left-lateralized activity in the praxis hub-i.e., the supramarginal gyrus (Bohlhalter et al., 2009; Króliczak \& Frey, 2009; Biduła \& Króliczak, 2015; Chen et al., 2016; Przybylski \& Króliczak, 2017; Buchwald et al., 2018; Potok et al., 2019; Garcea et al., 2020; Amaral et al., 2021; Króliczak et al., 2021a; see also Lesourd et al., 2021). By looking at all these results, one can argue that except for the supramarginal gyrus itself, and its immediate vicinity (i.e., areas PF and PFt, and PFcm or AIP), numerous areas of the praxis network contribute to the task in a bilateral or mixed manner, regardless of the lateralization of activity in its main hub (Binkofski \& Buxbaum, 2013; see also Garcea \& Buxbaum, 2019; Malfatti \& Turella, 2021; Amaral et al., 2021; cf. Riccardi et al., 2020). Furthermore, even if there is greater variability in the functioning of the praxis network, our analyses seem to indicate that it is contingent on the organization of language (cf. Fig. 2CD, 2EF). In fact, based on our earlier and current results, we are convinced that - as a related function, sharing some processing resources with praxis skills - the organization of language should be also taken onto account while searching for neural or cognitive mechanisms unique for atypical organization of praxis (Króliczak et al., 2021a).

Whether or not the organization of language really matters when these two functions dissociate (Figures 2C and 2D) is a question for a completely different debate. After all, aphasia can be found also after right-sided lesions, but this deficit will typically be only transient. Similarly, neglect after left-sided lesions will be typically transient, too (Liew et al., 2018). Yet, when both praxis and language are atypically organized or lateralized (Figures $2 \mathrm{E}$ and 2F; see also Klichowski et al., 2020), neurorehabilitation researchers and practitioners should probably pay greater attention to subcortical structures, as well. Otherwise, developing patient-based, neuro-rehabilitation techniques or neuroprostheses may not be as efficient as possible (Homberg, 2013).

\section{CONCLUSIONS}

The outcomes presented here substantially weaken a concern that merging quite heterogenous individuals with atypical representations of functions may hinder the proper understanding of the neural mechanisms responsible for atypically organized praxis or language. If one knows how many individuals from the bilateral and right-lateralized sample contribute to the average, and understands how these patterns differ from typically lateralized praxis or language, then it should be possible to apply proper weights to critical areas or regions responsible for the control of 
these functions. Because individuals with bilateral functional organization do not seem to differ much both from the ones with left- and right-lateralized representations, effective neuro-rehabilitation techniques and/or neuroprostheses should aim to account for the gradient of changes, depending on how bilateral or lateralized a given individual was. Last but not least, perhaps except for cases in which praxis and language clearly dissociate, praxis-language relationships should be always taken into equations.

\section{Acknowledgements}

The conclusions of this paper are consistent with the proposals and statements presented just over ten years ago during the "Brain Days 6" conference at KUL, Poland. The first author of this paper gave a research talk entitled "Sinistrals are right! fMRI reveals consistent cerebral lateralization of language and praxis in left-handers", following an invitation from the late Piotr Francuz. Because Prof. Francuz truly appreciated these lines of research, this work is dedicated to his memory.

\section{CRediT Author Statement}

GREGORY KRÓLICZAK (55\%): conceptualization, funding acquisition, methodology, validation, project administration, investigation, formal analysis, resources, visualization, writing (original draft), supervision, writing (review and editing).

MiKolaJ Buchwald (10\%): software, resources.

MichA£ KLICHOWSKI (10\%): formal analysis, writing (original draft), writing (review and editing).

AgNiESZKA M. NowIK (10\%): project administration, resources, methodology, data curation.

BRIAN J. PIPER (15\%): conceptualization, investigation, methodology, validation, formal analysis, writing (review and editing).

\section{REFERENCES}

Amaral, L., Bergstrom, F., \& Almeida, J. (2021). Overlapping but distinct: Distal connectivity dissociates hand and tool processing networks. Cortex, 140, 1-13. https://doi.org/10.1016/j.cortex.2021.03.011 
Badzakova-Trajkov, G., Haberling, I. S., Roberts, R. P., \& Corballis, M. C. (2010). Cerebral asymmetries: Complementary and independent processes. PLoS ONE, 5(3), e9682. https://doi.org/10.1371/ journal.pone. 0009682

Biduła, S. P., \& Króliczak, G. (2015). Structural asymmetry of the insula is linked to the lateralization of gesture and language. European Journal of Neuroscience, 41(11), 1438-1447. https://doi. org/10.1111/ejn.12888

Biduła, S. P., Przybylski, L., Pawlak, M. A., \& Króliczak, G. (2017). Unique neural characteristics of atypical lateralization of language in healthy individuals. Frontiers in Neuroscience, 11, 525. https://doi.org/10.3389/fnins.2017.00525

Binkofski, F., \& Buxbaum, L. J. (2013). Two action systems in the human brain. Brain \& Language, 127(2), 222-229. https://doi.org/10.1016/j.bandl.2012.07.007

Bohlhalter, S., Hattori, N., Wheaton, L., Fridman, E., Shamim, E. A., Garraux, G., \& Hallett, M. (2009). Gesture subtype-dependent left lateralization of praxis planning: an event-related fMRI study. Cerebral Cortex, 19(6), 1256-1262. https://doi.org/10.1093/cercor/bhn168

Buchwald, M., Przybylski, L., \& Króliczak, G. (2018). Decoding brain states for planning functional grasps of tools: A functional magnetic resonance imaging multivoxel pattern analysis study. Journal of the International Neuropsychological Society, 24(10), 1013-1025. https://doi.org/10.1017/ S1355617718000590

Cai, Q., Van der Haegen, L., \& Brysbaert, M. (2013). Complementary hemispheric specialization for language production and visuospatial attention. Proceedings of the National Academy of Sciences (USA), 110(4), E322-330. https://doi.org/10.1073/pnas.1212956110

Carey, D. P., \& Johnstone, L. T. (2014). Quantifying cerebral asymmetries for language in dextrals and adextrals with random-effects meta analysis. Frontiers in Psychology, 5, 1128. https://doi. org/10.3389/fpsyg.2014.01128

Chen, Q., Garcea, F. E., \& Mahon, B. Z. (2016). The representation of object-directed action and function knowledge in the human brain. Cerebral Cortex, 26(4), 1609-1618. https://doi.org/10.1093/ cercor/bhu328

Chlebus, P., Mikl, M., Brazdil, M., Pazourkova, M., Krupa, P., \& Rektor, I. (2007). fMRI evaluation of hemispheric language dominance using various methods of laterality index calculation. Experimental Brain Research, 179(3), 365-374. https://doi.org/10.1007/s00221-006-0794-y

Eklund, A., Nichols, T. E., \& Knutsson, H. (2016). Cluster failure: Why fMRI inferences for spatial extent have inflated false-positive rates. Proceedings of the National Academy of Sciences (USA), 113(28), 7900-7905. https://doi.org/10.1073/pnas.1602413113

Garcea, F. E., \& Buxbaum, L. J. (2019). Gesturing tool use and tool transport actions modulates inferior parietal functional connectivity with the dorsal and ventral object processing pathways. Human Brain Mapping, 40(10), 2867-2883. https://doi.org/10.1002/hbm.24565

Garcea, F. E., Greene, C., Grafton, S. T., \& Buxbaum, L. J. (2020). Structural disconnection of the tool use network after left hemisphere stroke predicts limb apraxia severity. Cerebral Cortex Communications, 1(1), tgaa035. https://doi.org/10.1093/texcom/tgaa035

Gerrits, R., Verhelst, H., \& Vingerhoets, G. (2020). Mirrored brain organization: Statistical anomaly or reversal of hemispheric functional segregation bias? Proceedings of the National Academy of Sciences (USA), 117(25), 14057-14065. https://doi.org/10.1073/pnas.2002981117

Goldenberg, G. (2013). Apraxia in left-handers. Brain, 136, 2592-2601. https://doi.org/10.1093/brain/ awt181

Goodale, M. A., Króliczak, G., \& Westwood, D. A. (2005). Dual routes to action: contributions of the dorsal and ventral streams to adaptive behavior. Progress in Brain Research, 149, 269-283. https://doi.org/10.1016/S0079-6123(05)49019-6 
Haberling, I. S., \& Corballis, M. C. (2015). Cerebellar asymmetry, cortical asymmetry and handedness: Two independent networks. Laterality: Asymmetries of Body, Brain and Cognition, 19, 1-18. https://doi.org/10.1080/1357650X.2015.1110161

Homberg, V. (2013). Neurorehabilitation approaches to facilitate motor recovery. Handbook of Clinical Neurology, 110, 161-173. https://doi.org/10.1016/B978-0-444-52901-5.00014-9

Jenkinson, M., Beckmann, C. F., Behrens, T. E., Woolrich, M. W., \& Smith, S. M. (2012). Fsl. Neuroimage, 62(2), 782-790. https://doi.org/10.1016/j.neuroimage.2011.09.015

Johnstone, L. T., Karlsson, E. M., \& Carey, D. P. (2020). The validity and reliability of quantifying hemispheric specialisation using fMRI: Evidence from left and right handers on three different cerebral asymmetries. Neuropsychologia, 138, 107331. https://doi.org/10.1016/j.neuropsycho logia.2020.107331

Johnstone, L. T., Karlsson, E. M., \& Carey, D. P. (2021). Left-handers are less lateralized than righthanders for both left and right hemispheric functions. Cerebral Cortex, 31(8), 3780-3787. https:// doi.org/10.1093/cercor/bhab048

Karlsson, E. M., Johnstone, L. T., \& Carey, D. P. (2019). The depth and breadth of multiple perceptual asymmetries in right handers and non-right handers. Laterality, 24(6), 707-739. https://doi.org/ 10.1080/1357650X.2019.1652308

Kimura, D. (1983). Speech representation in an unbiased sample of left-handers. Human Neurobiology, 2(3), 147-154. http://www.ncbi.nlm.nih.gov/entrez/query.fcgi?cmd=Retrieve\&db=PubMed\&dopt $=$ Citation\&list_uids $=6668232$

Klichowski, M., Nowik, A. M., Króliczak, G., \& Lewis, J. (2020). Functional lateralization of toolsound and action-word processing in a bilingual brain. Health Psychology Report, 8(1), 10-30. https://doi.org/10.5114/hpr.2020.92718

Knecht, S., Drager, B., Deppe, M., Bobe, L., Lohmann, H., Floel, A., Ringelstein, E. B., \& Henningsen, H. (2000). Handedness and hemispheric language dominance in healthy humans. Brain, 123, 25122518. https://doi.org/10.1093/brain/123.12.2512

Króliczak, G., Buchwald, M., Kleka, P., Klichowski, M., Potok, W., Nowik, A. M., Randerath, J., \& Piper, B. J. (2021a). Manual praxis and language-production networks, and their links to handedness. Cortex, 140, 110-127. https://doi.org/10.1016/j.cortex.2021.03.022

Króliczak, G., Buchwald, M., Kleka, P., Klichowski, M., Potok, W., Nowik, A. M., Randerath, J., \& Piper, B. J. (2021b). Manual praxis and language-production networks: An fMRI dataset. https://doi.org/10.17605/OSF.IO/63HJT

Króliczak, G., \& Frey, S. H. (2009). A common network in the left cerebral hemisphere represents planning of tool use pantomimes and familiar intransitive gestures at the hand-independent level. Cerebral Cortex, 19(10), 2396-2410. https://doi.org/10.1093/cercor/bhn261

Króliczak, G., Gonzalez, C., \& Carey, D. (2019). Editorial: Manual Skills, Handedness, and the Organization of Language in the Brain. Frontiers in Psychology, 10:930, 1-4. https://doi.org/10.3389/ fpsyg.2019.00930

Króliczak, G., Piper, B. J., \& Frey, S. H. (2011). Atypical lateralization of language predicts cerebral asymmetries in parietal gesture representations. Neuropsychologia, 49(7), 1698-1702. https://doi. org/10.1016/j.neuropsychologia.2011.02.044

Króliczak, G., Piper, B. J., Potok, W., Buchwald, M., Kleka, P., Przybylski, L., \& Styrkowiec, P. P. (2020). Praxis and language organization in left-handers. Acta Neuropsychologica, 18(1), 15-28. https://doi.org/10.5604/01.3001.0013.9738

Króliczak, G., Potok, W., \& Nowik, A. M. (2020). Język, praksja i ręczność: Delikatna triada z perspektywy leworęczności. Kosmos, 69(1), 123-134. https://doi.org/10.36921/kos.2020_2630 
Lesourd, M., Servant, M., Baumard, J., Reynaud, E., Ecochard, C., Medjaoui, F. T., Bartolo, A., \& Osiurak, F. (2021). Semantic and action tool knowledge in the brain: Identifying common and distinct networks. Neuropsychologia, 159, 107918. https://doi.org/10.1016/j.neuropsycholo gia.2021.107918

Liew, S. L., Garrison, K. A., Ito, K. L., Heydari, P., Sobhani, M., Werner, J., Damasio, H., Winstein, C. J., \& Aziz-Zadeh, L. (2018). Laterality of poststroke cortical motor activity during action observation is related to hemispheric dominance. Neural Plasticity, 2018, 3524960. https://doi.org/10.1155/2018/3524960

Malfatti, G., \& Turella, L. (2021). Neural encoding and functional interactions underlying pantomimed movements. Brain Structure and Function, 226(7), 2321-2337. https://doi.org/10.1007/s00429021-02332-6

Mazoyer, B., Zago, L., Jobard, G., Crivello, F., Joliot, M., Perchey, G., Mellet, E., Petit, L., \& Tzourio-Mazoyer, N. (2014). Gaussian mixture modeling of hemispheric lateralization for language in a large sample of healthy individuals balanced for handedness. PLOS ONE, 9(6), e101165. https:// doi.org/10.1371/journal.pone.0101165

Oldfield, R. C. (1971). The assessment and analysis of handedness: The Edinburgh inventory. Neuropsychologia, 9, 97-113. https://doi.org/10.1016/0028-3932(71)90067-4

Osiurak, F., Cretel, C., Uomini, N., Bryche, C., Lesourd, M., \& Reynaud, E. (2021). On the neurocognitive co-evolution of tool behavior and language: Insights from the Massive Redeployment Framework. Topics in Cognitive Science, 13(4), 684-707. https://doi.org/10.1111/tops.12577

Potok, W., Maskiewicz, A., Króliczak, G., \& Marangon, M. (2019). The temporal involvement of the left supramarginal gyrus in planning functional grasps: A neuronavigated TMS study. Cortex, 111, 16-34. https://doi.org/10.1016/j.cortex.2018.10.010

Przybylski, L., \& Króliczak, G. (2017). Planning functional grasps of simple tools invokes the hand-independent praxis representation network: an fMRI study. Journal of the International Neuropsychological Society, 23(2), 108-120. https://doi.org/10.1017/S1355617716001120

Riccardi, N., Yourganov, G., Rorden, C., Fridriksson, J., \& Desai, R. (2020). Degradation of praxis brain networks and impaired comprehension of manipulable nouns in stroke. Journal of Cognitive Neuroscience, 32(3), 467-483. https://doi.org/10.1162/jocn_a_01495

Rizzolatti, G., \& Matelli, M. (2003). Two different streams form the dorsal visual system: anatomy and functions. Experimental Brain Research, 153(2), 146-157. https://doi.org/10.1007/s00221003-1588-0

Thirion, B., Pinel, P., Meriaux, S., Roche, A., Dehaene, S., \& Poline, J. B. (2007). Analysis of a large fMRI cohort: Statistical and methodological issues for group analyses. Neuroimage, 35(1), 105-120. https://doi.org/10.1016/j.neuroimage.2006.11.054

Vingerhoets, G. (2019). Phenotypes in hemispheric functional segregation? Perspectives and challenges. Physics of Life Reviews, 30, 1-18. https://doi.org/10.1016/j.plrev.2019.06.002

Vingerhoets, G., Alderweireldt, A. S., Vandemaele, P., Cai, Q., Van der Haegen, L., Brysbaert, M., \& Achten, E. (2013). Praxis and language are linked: evidence from co-lateralization in individuals with atypical language dominance. Cortex, 49(1), 172-183. https://doi.org/10.1016/j. cortex.2011.11.003

Woodhead, Z. V. J., Thompson, P. A., Karlsson, E. M., \& Bishop, D. V. M. (2021). An updated investigation of the multidimensional structure of language lateralization in left- and right-handed adults: a test-retest functional transcranial Doppler sonography study with six language tasks. Royal Society Open Science, 8:200696. https://doi.org/10.1098/rsos.200696 